\title{
Trust in the State Courts: Hispanic and African American Communities
}

\author{
Ivanka Bergova \\ Georgia State University, Atlanta, Georgia, USA
}

\begin{abstract}
The paper aims to compare the levels of trust Caucasians, African Americans, Hispanics, and other minority groups have in state courts. The paper presents four hypothesize which contend that African Americans, Hispanics, and other minority groups have lower levels of trust in state courts in comparison to Caucasians. Using data from a 2001 Justice at Stake Public Survey, a multivariate regression analysis was performed to assess the validity of each hypothesis. The variable for Race/Ethnicity was used as a baseline allowing for the comparison of levels of trust among each racial/ethnic group. The findings indicate that African Americans have a lower level of trust in state courts in comparison to their Caucasian and other minority counterparts and vice versa. Surprisingly, Hispanics were found to have no more or less trust in state courts when compared to Caucasians, African Americans, and other minority groups. Further research regarding trust in state courts should be carried out in both African American and Hispanic communities. Lastly, it is noteworthy to mention that the data set contained some limitations, such as its age and the exclusion of "Asian" in the racial/ethnic categories.
\end{abstract}

Keywords: state courts, trust, minorities, African Americans, Hispanics

\section{Introduction}

Public trust in the courts serves as the court's ultimate source of power. The public's trust in the American court system, both federal and state, gives the institution a means of legitimization. For these reasons, public trust in the American courts has been a long-standing research topic for political scientists. Despite the topic's popularity, researchers looking at public trust in the courts have mainly focused on examining trust in the United States Supreme Court. In those studies, the effects of race/ethnicity are rarely accounted for. Studies which take race/ethnicity into account generally include only Caucasians and African-Americans. These studies evaluate the racial group's individual trust in the United States Supreme Court and compare it to one another. Few studies examining public trust in the American court system have looked at trust in state courts. Similar to studies examining trust in the United States Supreme Court, studies dealing with trust in local courts have either ignored the effects of race/ethnicity or only included Caucasians and African Americans as racial groups. Although informative and comprehensive, these studies fail to highlight the importance of examining trust in state courts and controlling for the effects of race/ethnicity.

By not accounting for the effects of race/ethnicity on the levels of trust in state courts, researchers have ignored an important question: in comparison to one another, do racial/ethnic groups in the United States have similar or different levels of trust in state courts? The question bares significance for two reasons: (1)

Ivanka Bergova, Bachelor of Arts, Department of Political Science, Georgia State University. 
race/ethnicity has a large impact on the country's political system; (2) individuals are more likely to have a greater interaction with state courts rather than the Supreme Court (Enomoto, 1999; Oberby et al., 2004). The United States has had a long and turbulent history with race and ethnicity. Policies and practice carried out by the American criminal justice system have had lasting effects on minorities in the country. In the African American community, the assertion that the American justice system unfairly targets African Americans is not uncommon. Accounting of the country's historic oppression of African Americans in the forms of slavery, Jim Crow laws, and numerous cases like Rodney King where an all - Caucasian jury failed to prosecute several officers for the brutal beating of King, it is difficult to fight the growing assertion that the criminal justice system in America is color-blind (Enomoto, 1999; Barnes \& Chemerinsky, 2009).

Similar to African Americans, Hispanics in the United States have also been subject to discriminatory practices and policies throughout the country's history. In the past, Hispanics have faced large deportation programs such as the Mexican Repatriation in the 1930s and Operation Wet Back in the 1950s (Rumbaut \& Portes, 2014). In recent years, Hispanics have also been targeted through state legislation. California, among several states, signed into law state legislations, targeting Hispanics. These legislations included "making the state's official language English, anti-affirmative initiatives", and restrictions on providing illegal immigrants any social assistances in the forms of healthcare or welfare, and intensive ELL programs for the children of immigrants (Martinez-Ebers et al., 2000). Other states like Georgia have in the past required that $75 \%$ of business signs be in English and enacted county ordinances restricting the number of people who can live in one place. More recently, the state of Georgia's legislators proposed and passed the Georgia Security and Immigration Compliance Act (Bill 529) which would manage illegal immigration in the state (Odem, 2008). Iowa, similar to a number of other states, in 2002 passed state legislation making English the official language of the state. On the federal level, legislators in 2005 passed the Sensenbrenner bill which criminalized immigration to the country through illegal means (Rumbaut \& Portes, 2014). These actions, on behalf of state and federal governments, have supported discriminatory practices towards Hispanics in the United States. Considering the past and present treatment of African Americans and Hispanics in the United States, resentment towards the country's criminal justice system is no surprise.

\section{Literature Review}

Tyler's (1988) study explores the meaning behind procedural justices for individuals, concluding that its meaning is dependent upon the circumstances of a situation. In a general study of trust in the courts, Olson and Huth (1998) found that perception of fairness for local courts is bares significance. The study also found that prior experience with local courts had a large influence on an individual's perception of fairness. Based on this significance, it is important to note that previous contact with the courts must be controlled for. While a number of studies have been conducted on the levels of general trust in the courts, few have look at minority groups and their levels of trust in local courts. A large number of studies examining minority groups' trust in local courts have evaluated African Americans while excluding evaluations of other racial/ethnic groups. These studies compared the level of trust African Americans held for local courts to that of Caucasians. Additionally, these studies assessed whether racial bias has an influence on Caucasian's trust in local courts.

Hurwitz and Peffley (2005), Federico and Holmes (2005), Benesh (2006), Henderson et al. (1997), Young (1991), Overby et al. (2004), Rottman and Tomkins (1999), Enomoto (1999), and Gibson and Caldiera (1992) are some of the studies which have looked at African Americans and Caucasian's level of trust in local courts 
and whether bias plays a role in that trust. In an overall study of the courts, Overby et al. (2004) found that African Americans were much less likely to trust local courts. Overby et al. (2004)'s findings were supportive of Rottoman and Tomkins (1999)'s study which also found African Americans to be less trusting of local courts. Additionally, Rottoman and Tomkins (1999)'s study indicated that African Americans held a negative view towards local courts and were found to have less trust in the criminal justice system as a whole. Young (1991) suggests that African Americans are significantly more likely to believe sentencing injustice exists in the court system. One possible explanation for Young (1991)'s findings can be derived from African Americans increased interaction with the criminal justice system. As a whole, African Americans have a high in carceration rate and are more likely to experience crimes committed against them thus, elevating their interactions with the criminal justice system. As supported by Fagan (1981)'s study, individuals concerned with crime and having a fear of crime were less likely to view the courts favorably. The high rate of incarceration and victimization in the African American community supports the notion that African Americans have low levels of trust in local courts. Despite the low levels of trust in local courts, Gibson and Caldiera (1992) found that African Americans were more likely to hold favorable views of the United States Supreme Court. These findings are connected with Supreme Court's policy making in support of Civil Rights for African Americans in the country.

Gibson and Caldiera (1992)'s study also highlights the diffused support for the United States' Supreme Court between racial groups. The study found that, in comparison to African Americans, Caucasians were less likely to have a favorable view of the Supreme Court. Studies analyzing Caucasian's views towards the American criminal justice system, find recognition of differential treatment of African Americans and the presence of bias. Henderson et al. (1997)'s study examines the views Caucasians hold towards the court system. The study's findings indicate that Caucasian respondents believed that African Americans were subject to differential treatment in the criminal justice system. In the same study, Caucasian respondents expressed a belief that they were not subject to any unjust acts by the criminal justice system when compared to African Americans. Young (1991)'s study found that Caucasian respondent's attitudes were more likely to be shaped by "issues of criminal motivation" (Young, 1991, p. 72). Hurwitz and Peffley (2005) found that Caucasian respondents were "less likely to predict a fair investigation against a white motorist" or "they're actually more punitive against the officer who brutalizes a black civilian than an officer who brutalizes a white civilian" (p. 777). These studies suggest the presence of an in-group bias in Caucasian respondents. Federico and Holmes (2005) study further confirms the presence of an in-group bias for Caucasian respondents. The study found that individuals who held negative stereotypes of African Americans participated in an in-group bias. Federico and Holmes (2005) suggest that these findings are likely to be the result of media consumption in which African Americans are portrayed as the "bad guy".

Federico and Holmes (2005)'s study also found linkage between educational levels of respondents and whether they held negative stereotypes of African Americans. The study found that individuals with high levels of education were less likely to harbor any negative stereotypes regarding African Americans. To further confirm the importance of education, Benesh (2006) found that individuals that hold more knowledge regarding the courts, have positive experiences with the criminal justice system, "lives within an area with low crime rates, and lives within a state where judges are appointed" indicate higher levels of confidence within their local courts (p. 704). Enomoto's (1999) study also found age, gender, and income to matter. The study looked at 
public responses to the O. J. Simpson trial and its verdict. The study found that older individuals were less likely to express any sympathy for O. J. Simpson's situation. In regard to gender, the study found that women were more likely to express sympathy for O. J.'s situation as opposed to men, who were less likely to be sympathetic with his situation. Additionally, the study indicated that individuals with higher incomes were less likely to sympathize with O. J. Consequently, these studies only included the analysis of African Americans and Caucasian's level of trust in local courts.

Although a number of studies examine the trust in the courts based on race, the majority of these studies only look at African American and Caucasian groups in terms of race. Few studies have included a third minority group. Sun and Wu (2006), Buckler et al. (2007) Wenzel (2003) and Tyler (2001) have all included a third minority when examining trusts in the courts. In all the studies, Hispanics were included along with African Americans and Caucasians. Sun and Wu's study found that "... racial minorities, including Blacks and Latinos, were more likely than Whites to have negative attitudes towards the courts" (Sun \& Wu, 2006, p. 465). This particular study corroborates the findings of previous studies that past experience with the criminal justice system bares an effect on a respondent's trust in their local courts (Sun \& Wu 2006). Despite the significant influence of one's opinion of the court and their previous involvement with the court, as found in Sun and Wu's study, Buckler et al. (2007) found that the pervious encounters with the criminal justice system were mildly significant. The study indicated that beliefs in discrimination strongly influenced one's view of the court, particularly with African Americans and Hispanics.

In a semi-contradictory manner, Tyler (2001)'s study found that Hispanics are more likely to base their opinions of the courts and their perception of fairness on "the quality of treatment people received from the courts" (Tyler, 2001, p. 228).Hispanics differed from African Americans in that African Americans were more likely to base their opinions regarding the court on their judgment of differential group treatment (Tyler, 2001).To further contradict Sun and Wu's findings, Wenzel et al. (2003) found that Hispanics were more likely to view local courts in a positive manner while, African Americans were more likely to hold negative views towards local courts. In addition to the diverse findings presented by previous studies, Menjivar and Bejarano (2004)'s study highlights the importance of past experience with the criminal justice system and the importance of citizenship status. The study suggests that Latin-American immigrants and refugees have less favorable views of the criminal justice system. Additionally, citizenship status also bears significance in whether an individual has a favorable or unfavorable view of the American criminal justice system. Consequently, studies examining the degree of trust in courts held by Hispanics have all produced different findings. All of the studies mentioned in this section have presented a number of significant variables to be accounted for. Based on these studies, the variables for education, race, age, gender, knowledge of the courts, prior involvement with the courts or the criminal justice system, and influence of money must all be accounted for.

\section{Hypothesis}

As touched on by a number of studies African Americans hold the highest incarceration rates in the country. African Americans make up 13\% of the country's total population yet African American males comprise $37 \%$ and African American females makeup 21\% of the country's prison population. African American males, in particular, have the highest incarceration rates in all age groups in both state and federal prisons (Bureau of Justice Statistics 2014; United States Census Bureau 2014). Hispanics to experience high 
levels of incarceration while only accounting for $17 \%$ of the population. Twenty-two percent of the country's total prison population is made up of Hispanic males and $17 \%$ is made up of Hispanic females (Bureau of Justice Statistics 2014; United States Census Bureau 2014). I therefore draw on differential experience, which suggests that an individual's view of the court and legal system as a whole is largely influenced by their experience with the criminal justice system and the courts (Sun \& Wu, 2006). Based on this theory, African Americans and Hispanics are likely to be distrustful of the courts given the disproportionate incarceration rates, perception of bias, and injustice and are thus, more likely to hold a negative view of the courts than Caucasians. I also expect to find that African Americans hold a lower level of trust within local courts in comparison to other minority group members. Despite the mixed findings of previous studies which include Hispanics, I expect Hispanics to hold a lower level of trust for local courts in comparison to Caucasians and other minority groups. Additionally, I expect to find that other minority groups (with non-specified race/ethnicity) to have a lower level of trust in the courts in comparison to Caucasians, Hispanics, and African American respondents.

\section{Dependent Variable}

The dependent variable for this study is the level of trust and confidence in state courts. The variable is measured using a question asking respondents how much trust and confidence they have in courts and judges in their state. The responses for this question is coded as $1=$ None at All, $2=$ Just a Little, $3=$ Some, $4=$ A Great Deal (see Appendix 1 for the complete list of the survey questions, recordings of variables, and the independent variables used for the study). The dependent variable for this study was presented in a 2001"Justice at Stake Frequency Questioner" survey. The sample size of the study contains 973 respondents. Seven hundred ninety one respondents to the survey identified themselves as Caucasian, 90 respondents identified themselves as African American, 38 respondents identified themselves as Hispanic, and 54 respondents identified themselves as another racial/ethnic group that was not specified in the survey.

Prior to using Ordinary Least Squares to test my hypotheses, I conducted several independent sample T-tests to evaluate whether different racial/ethnic groups differ in their trust for the courts in comparison to one another. Tables 1 through 4 show the results of the independent sample T-tests. Equal variance is not assumed for each race/ethnicity's t-test, because the significance ranges from 0.000 to 0.001 , both of which are smaller than the p-value of 0.05 . The 2-tailed significance for each race/ethnicity is shown as 0.000 , less than 0.05.Consequently, the independent sample T-test conducted shows that there are statistically significant differences between the means of respondents belonging to each racial/ethnic category.

Table 1

Independent Sample T-Test: The Variable for Caucasians is Used as a Baseline

\begin{tabular}{|l|l|l|l|l|}
\hline & Significance & Significance (2-Tailed) & Mean difference & Standard error difference \\
\hline $\begin{array}{l}\text { Caucasian and African } \\
\text { American respondents }\end{array}$ & 0.000 & 0.000 & -0.89581 & 0.01029 \\
\hline $\begin{array}{l}\text { Caucasians and Hispanic } \\
\text { respondents }\end{array}$ & 0.000 & 0.000 & -0.84599 & 0.01181 \\
\hline $\begin{array}{l}\text { Caucasians and Other } \\
\text { Race/Ethnicity } \\
\text { respondents }\end{array}$ & 0.000 & 0.000 & -0.86072 & 0.01143 \\
\hline
\end{tabular}

Note. ${ }^{*}$ Equal variance is not assumed since the significance is 0.000 or is less than $0.05 ; N=973$ 
Table 2

Independent Sample T-Test: The Variable for African Americans is used as Baseline

\begin{tabular}{|l|l|l|l|l|}
\hline & Significance & Significance (2-tailed) & Mean Difference & Standard error difference \\
\hline $\begin{array}{l}\text { African American and } \\
\text { Caucasian respondents }\end{array}$ & 0.000 & 0.000 & -0.49451 & 0.03716 \\
\hline $\begin{array}{l}\text { African Americans and } \\
\text { Hispanics respondents }\end{array}$ & 0.000 & 0.000 & -0.09629 & 0.00965 \\
\hline $\begin{array}{l}\text { African Americans and } \\
\text { Other Race/Ethnicity } \\
\text { respondents }\end{array}$ & 0.000 & 0.000 & -0.09793 & 0.00981 \\
\hline
\end{tabular}

Note. $*$ Equal variance is not assumed since the significance is 0.000 and less than $0.05 ; N=973$.

Table 3

Independent Sample T-Test: The Variable for Hispanic is Used as Baseline

\begin{tabular}{|l|l|l|l|l|}
\hline & Significance & Significance (2-tailed) & Mean difference & Standard error difference \\
\hline $\begin{array}{l}\text { Hispanic and Caucasian } \\
\text { respondents }\end{array}$ & 0.000 & 0.000 & 0.20879 & 0.03021 \\
\hline $\begin{array}{l}\text { Hispanic and African } \\
\text { American respondents }\end{array}$ & 0.000 & 0.000 & -0.04304 & 0.00683 \\
\hline $\begin{array}{l}\text { Hispanic and Other } \\
\text { Race/Ethnicity } \\
\text { respondents }\end{array}$ & 0.001 & 0.000 & -0.04135 & 0.00657 \\
\hline
\end{tabular}

Note. $*$ Variance is not assumed since the significance is 0.000 or less than $0.05 ; N=973$.

Table 4

Independent Sample T-Test: The Variable for Other Race/Ethnicity is used as Baseline

\begin{tabular}{|l|l|l|l|l|}
\hline & Significance & Significance (2-taled) & Mean Difference & Standard error difference \\
\hline $\begin{array}{l}\text { Other Race/Ethnicity and } \\
\text { Caucasian respondents }\end{array}$ & 0.000 & 0.000 & -0.29670 & 0.03395 \\
\hline $\begin{array}{l}\text { Other Race/Ethnicity and } \\
\text { African American } \\
\text { respondents }\end{array}$ & 0.000 & 0.000 & -0.06116 & 0.00807 \\
\hline $\begin{array}{l}\text { Other Race/Ethnicity and } \\
\text { Hispanic respondents }\end{array}$ & 0.001 & 0.000 & -0.05775 & 0.00763 \\
\hline
\end{tabular}

Note. *Equal variance is not assumed since the significance is 0.000 or is less than $0.05 ; N=973$.

\section{Independent Variables}

In this study, the respondents' race/ethnicity was the main area of concern in predicting the trust and confidence in local courts. A number of previous studies have found fairly consistent results for African American respondents. Previous studies concerning Hispanics and their trust in local courts have had a number of inconsistent results. Studies conducted by Hurwitz and Peffley (2005), Federico and Holmes (2005), Benesh (2006), Henderson et al. (1997), Young (1991), Overby et al. (2004), Rottman et al. (1999), Enomoto (1999), and Gibson and Caldiera (1992) have all found fairly consistent responses regarding African Americans and their level of trust in local courts, as well as the Supreme Court. The majority of the studies indicate that African American respondents held little trust in their state courts. The studies conducted by Sun and Wu (2006), Buckler et al. (2007), Wenzel (2003), and Tyler (2001) have drawn different outcomes regarding Hispanics and their level of trust in local courts.

In addition to controlling for race/ethnicity, several other variables must also be controlled for in order to understand what drives trust or lack thereof in state courts and judges. These variables include knowledge about state courts and judges, level of education, influence of money on judicial decisions, religious service 
attendance, age and gender. In previous studies, knowledge of the courts and judges was shown to bear significance in the attitudes individuals held regarding the courts. Benesh (2006)'s study shows that individuals who have a better understanding of how the courts and judges operate are more likely to hold a positive view of them. In comparison, individuals who have a limited understating of how courts operate are more likely to have a negative view of courts and judges all together. Thus, knowledge about the courts and judges may have a significant effect on how individuals perceive of the judicial system, and I expect that increased knowledge leads to more positive evaluations of the courts. The level of education individuals complete may also have a significant effect on their view of the court system. In a number of previous studies, individuals with higher education are shown to have a higher likelihood of having a positive attitude towards the judicial system. Individuals with lower levels of education, on the other hand, are more likely to hold more negative attitudes towards the judicial system (Benesh, 2006).

Individuals' perception of influence of money on judicial decision making is also anticipated to have an effect on the level of trust individuals hold towards local courts. Monetary campaign contributions to judges in local courts are often seen has having an influence over that judge's decisions on the bench. Consequently, individuals who live in areas where judges accept monetary contributions are likely hold negative view of the judge and court in their residential area. This notion is derived from the perception that judges are supposed to be impartial individuals, by accepting monetary contributions judges are no longer impartial (Jamieson \&Hardy, 2008). Thus, the acceptance of monetary contributions by a judge dissolves their independent status, and leaves room for suspicion among the public.

The religious attendance of individuals is another variable which may have a significant effect on an individuals' level of trust towards local courts. Individuals who attend religious services often are through to have a higher sense of justice and morality; thus, they may have higher expectations of the courts in making the correct and moral decision in controversial cases (Wesinski et al., 2009). Young (1992) and Esienberg et al. (2001)'s studies on jurors and their attitudes towards the death penalty identified religion as an influential factor in determining a jurors vote. Consequently, religion may also influence the levels of trust individuals have towards their state courts. Religious individuals may expect the courts to decide controversial matters, such as the death penalty, abortion, or cases dealing with religious freedom on the grounds of morality; however, the courts seldom decide such cases on the grounds of morality. Given the adverse outcomes of controversial cases dealing with morality and religion, it is likely that religious individuals may have a lower level of trust in the courts.

Finally, I control for the respondents' age and gender. Enomoto (1999)'s study indicated that age should be controlled for. The study indicated that older individuals were less likely to sympathize with O.J's situation than younger individuals. Thus, the diffusion of support between younger and older individuals regarding O.J Simpson's racially polarized case suggests that age is an important factor in determining the level of trust individuals have in the court system. Additionally, Gibson and Caldeira (1992)'s findings hint at the importance in controlling for a respondents age. As mentioned previously, Gibson and Caldeira (1992)'s study found that African Americans held more favorable views towards the United States Supreme Court in comparison to Caucasians. African Americans' favorable views towards the Supreme Court are suggested to be the result of Supreme Court decisions supporting the Civil Rights Movement (Gibson \& Calderia 1992). Based on these studies, it is likely that respondent's age has an influence on individuals' level of trust in the courts. 
Enomoto (1999)'s study indicated that gender should also be controlled for. Enomoto (1999)'s study found that women were more likely to sympathize with O.J Simpson in comparison to men. Given the diffusion of sympathy for O.J Simpson based on gender, it is likely that gender could also have an influence on individuals' levels of trust in the courts. As mentioned previously in the study, incarceration rates among men, especially African American and Hispanics, are particularly high; male and female respondents could have fairly different levels of trust in the court (Bureau of Justice Statistics 2015). Consequently, based on the indications of Enomoto (1999)'s study it is important to control for the effects of respondents' age and gender.

\section{Variable Recoding and Types of Analysis Used}

The variable for trust and confidence in state courts was recorded so that unknown responses were dropped and the order reversed (see appendix for more information and list of recordings). The original variable for race/ethnicity was recorded into four dummy variables: Caucasian, African American, Hispanic, and Other race/ethnicity. The variable for education captures whether the respondent has a high or low level of formal education. Respondents with no college education were recorded as 1 (1st through 11th grade, high school graduates, high school graduates no college) and respondents who had a college education or higher were recorded as 0 (some college, college graduate, post-college education). The variable for age was also recoded - such as that respondents born in the years 1911 to 1967 were recorded as 0 and respondents born in the years 1968 to 1983 were recorded as 1 . The variables for influence of money in judicial decisions and knowledge about the courts and judges were recorded with 1 being coded for response of "A great deal" or "Some" and 0 being coded for response of "Just a little" or "None at all". For all of the variables, respondents who answered "don't know" or "refused" were dropped from the analysis.

Since the dependent variable, Trust in Courts, has four potential answers, I use Ordinary Least Squares to test my hypotheses. I estimated my main model four distinct times, in each estimation altering which of the racial/ethnic categories was used as the baseline for comparison purposes. The results from the multivariate analysis are displayed in tables 5, 6, 7, and 8. In Table 5 the variable for Caucasians serves as a baseline. In table 6, the variable for African Americans serves as the baseline. In table 7, the variable for Hispanics serves as the baseline and in table 8 the variable for other race/ethnicity serves as the baseline.

\section{Results}

Tables 5 through 8, pages 19 to 22, report the influences on each respondent's level of trust in their state courts and judges. As anticipated in my hypothesis, race/ethnicity had some significance in the level of trust individuals have for their state courts. In Table 5 and 6, I find that in comparison to Caucasian respondents, African American respondents had a lower level of trust in the courts. The findings pertaining to African American respondents in Table 5 and 6 match the results produced in previous studies by Overbyet al. (2004) and Rottman and Tomkins (1999). Table 6, which uses African Americans as the baseline, indicates that Caucasian respondents have a much greater level of trust in state courts in comparison to African Americans. Other racial/ethnic minority groups were also found to have more trust in state courts in comparison to African Americans. Conversely, Hispanic respondents were found to have no more or less trust in the state courts in comparison to African American respondents. Table 7 shows the findings of the effects of race/ethnicity on trust in state courts with Hispanics as the baseline. The findings in this table indicated that Caucasian, African American and Non-specified minority groups are no more or less trust in state courts in comparison to Hispanic 
respondents. Finally, in Table 8 other racial/ethnic minority groups are used as the baseline. The results shown in Table 8 indicate that Caucasian and Hispanic respondents bear no more or less trust in state courts in comparison to Non-specified minority groups. The findings also indicate that African Americans have a lower level of trust in state courts in comparison to Non-specified minority groups.

The hypotheses made earlier in the paper regarding race/ethnicity and its influence on trust in the courts are in part correct and in part incorrect. The first hypothesis regarding African American respondents and their level of trust in the courts was correct. African American respondents do in fact have a lower trust in state courts in comparison to Caucasians and other racial/ethnic minority groups. The second hypothesis regarding Hispanic respondents and their level of trust in state courts was in correct; however, Hispanic respondents hold lower levels of trust for state courts. The findings of the analysis were somewhat surprising; they indicated that Hispanic respondents had no more or less trust in the state courts when compared to Caucasian respondents (seeTable 5), African American respondents (see Table 6) and other racial/ethnic minority groups (see Table 8). The third hypothesis regarding other racial/ethnic minority groups and their level of trust in state courts was also incorrect. Surprisingly, the findings indicate that the respondents who identified with a non-specified minority group on the survey had no more or less support for state courts when compared to Caucasian respondents and Hispanic respondents (see Table 2, 4 and 5). Interestingly enough, non-specified minority group respondents were shown to hold a higher level of trust in state courts in comparison to their African American counterparts (see Table 3 and5). Thus, my hypotheses regarding race/ethnicities influence on levels of trust in state courts were in part correct and in part incorrect. However, what my analysis does make clear is that racial and ethnic minorities are not monolithic, and so future studies need to take into account potential differences among these groups, rather than lumping them together.

Gender and knowledge about the courts and judges do not appear to influence respondent's level of trust in state courts. The variable for age (birth years of 1968 to 1983) was shown to be borderline significant when it came to the level of trust in state courts. This finding is interesting, because based on Enomoto (1999)'s study and my own theory for individuals born after the Civil Rights Movement, I expected to find that individuals born after the Civil Rights Movement would have less trust in the courts as a result of high incarceration rates of minorities. What the study found instead is that the age is positively correlated with levels of trust and confidence in state courts. As the respondents age increases, the level of trust in the courts increases as well. The variable for education (no college) and influence of money in judicial decisions are shown to have statistical significance on the level of trust respondents have for state courts. The variable for education (no college) is shown to be positively correlated to trust and confidence in the courts. As an individuals' level of education increases, the level of trust in the courts increases as well. The study suggests that the more education an individual has, the more likely they are the trust state courts. Perhaps the most interesting findings from this study are the results pertaining to religious service attendance. Religious service attendance is negatively correlated with levels of trust for state courts; meaning that as, attendance in religious service increases for a respondent, their trust in state courts decreases. This finding suggests that individuals who attend religious service frequently are likely to have less trust in state courts. As discussed previously in the paper, this could likely result from various cases in which the courts have ruled in an unfavorable manner towards religious groups. 
Table 5

Determents for Trust and Confidence in the Courts: The Variable for Caucasian as Baseline

\begin{tabular}{|l|l|l|}
\hline & Coefficients (S.E) & Significance \\
\hline Race/Ethnicity: & $-0.662(0.196)$ & \\
African American & $-0.334(0.296)$ & $0.001^{*}$ \\
Hispanic & $-0.075(0.240)$ & 0.259 \\
Other Racial/Ethnic Groups & $-0.045(0.113)$ & 0.755 \\
\hline Socio -Demographic Values: & $0.300(0.118)$ & \\
Gender (Male) & $0.257(0.133)$ & 0.693 \\
Education (no college) & $-0.319(0.139)$ & $0.011^{*}$ \\
Age & $0.131(0.149)$ & 0.054 \\
Other Values: & $-0.138(0.047)$ & $0.022^{*}$ \\
Influence of Money on Judicial Decisions & 0.379 \\
Knowledge about the Courts and Judges & $0.003^{*}$ \\
\hline Religious Service Attendance & & \\
\hline
\end{tabular}

Note $. \mathrm{N}=973, *$ Statistical Significance $<0.05$, all p-values are based on a two tailed test.

Table 6

Determents for Trust and Confidence in the Courts: The Variable for African Americans as Baseline

\begin{tabular}{|c|c|c|}
\hline & Coefficient (S.E) & Significance \\
\hline $\begin{array}{l}\text { Race/Ethnicity: } \\
\text { Caucasian } \\
\text { Hispanic } \\
\text { Other Race/Ethnicity }\end{array}$ & $\begin{array}{l}0.662(0.196) \\
0.327(0.341) \\
0.587(0.298)\end{array}$ & $\begin{array}{l}0.001^{*} \\
0.338 \\
0.049^{*}\end{array}$ \\
\hline $\begin{array}{l}\text { Socio-Demographic Factors: } \\
\text { Gender (Male) } \\
\text { Education (no college) } \\
\text { Age } \\
\text { Other Values: } \\
\text { Influence of Money on Judicial Decisions } \\
\text { Knowledge about the Courts and Judges } \\
\text { Religious Service Attendance }\end{array}$ & $\begin{array}{l}-0.045(0.133) \\
0.300(0.118) \\
0.257(0.133) \\
-0.319(0.139) \\
0.131(0.149) \\
-0.138(0.047)\end{array}$ & $\begin{array}{l}0.693 \\
0.11 * \\
0.054 \\
\\
0.002^{*} \\
0.379 \\
0.003^{*}\end{array}$ \\
\hline
\end{tabular}

$N=973$, * Statistical Significance $<0.05$, all p-values are based on a two tailed test.

Table 7

Determents for Trust and Confidence in the Courts: The Variable for Hispanics as the Baseline

\begin{tabular}{|l|l|l|}
\hline & Coefficients (S.E) & Significance \\
\hline Race/Ethnicity: & $0.334(0.296)$ & \\
Caucasian & $-0.327(0.341)$ & 0.259 \\
African American & $0.259(0.369)$ & 0.338 \\
Other Race/Ethnicity & $-0.045(0.113)$ & 0.483 \\
\hline Socio-Demographic Factors: & $0.300(0.118)$ & 0.693 \\
Gender (Male) & $0.257(0.133)$ & $0.011^{*}$ \\
Education (no college) & $-0.319(0.139)$ & 0.054 \\
Age & $0.131(0.149)$ & $0.022^{*}$ \\
Other Factors: & $-0.138(0.047)$ & 0.379 \\
Influence of Money on Judicial Decisions & $0.003^{*}$ \\
\hline Knowledge about the Courts and Judges & Religious Service Attendance & \\
\hline
\end{tabular}

Note. $N=973$. $*$ Statistical Significance $<0.05$, all p-values are based on a two-tailed test.

The results presented above were in part consistent with previous studies. The findings indicating that African American respondents held lower levels of trust in state courts when compared to Caucasian respondents were consistent with the findings of Hurwitz et al. (2005), Federico et al. (2005), Benesh (2006), Henderson et al. (1997), Young (1991), Overby et al. (2004), Rottman and Tomkins (1999) and Enomoto 
(1999). The findings for Hispanic respondents were not consistent with the previous studies of Sun and Wu (2006); however, the findings were consistent with Wenzel (2003)'s study which found that Hispanics had higher levels of trust in state courts when compared to African Americans. Little can be said for the consistency of the findings for other racial/ethnic minority groups and their level of trust in state courts due to lack of research along with the uncertainty of which minority groups the variable includes. Additionally, the findings for age, education, and influence of money in judicial decisions were consistent with previous studies of Federico et al. (2005), Benesh (2006), and Enomoto (1999). The findings regarding the variables for knowledge about the courts and judges and gender were inconsistent with the previous study of Benesh (2006) and Enomoto (1999). Although knowledge about the courts and judges is positively correlated with trust and confidence in state courts, it does not appear to be significant. This may likely be the result of the study's inclusion of individuals with a formal education who've been exposed to knowledge about the American judicial system. Additionally, the variable may be overshadowed by a positive prior experience with the court system (which was not a surveyed question). However, this result suggest that further research should be conducted with a more divers sample, including several racial/ethnic groups, to conform this study's results for the variable for knowledge about the courts and judges. The variable for gender also does not appear to have a significance regarding levels of trust in state courts. The variable seems to be negatively correlated with trust in state courts: however, it does not appear to have a significant effect on trust in state courts. This may result from the fact that the study is looking only at general trust in state courts and not a particular case, as was the situation with Enomoto (1999)'s study which found gender diffusion in sympathy for O.J. Simpson.

Table 8

Determents for Trust and Confidence in the Courts: The variable for Other Race/Ethnicity

\begin{tabular}{|l|l|l|}
\hline & Coefficient (S.E) & Significance \\
\hline Race/Ethnicity: & $0.075(0.755)$ & 0.755 \\
Caucasian & $-0.587(0.298)$ & $0.049^{*}$ \\
African American & $-0.259(0.369)$ & 0.483 \\
Hispanic & $-0.045(0.133)$ & 0.693 \\
\hline Socio-Demographic Values: & $0.300(0.118)$ & $0.011^{*}$ \\
Gender (Male) & $0.257(0.133)$ & 0.054 \\
Education (no college) & $-.319(0.139)$ & $0.022^{*}$ \\
Age & $.131(0.149)$ & 0.379 \\
Other Values: & $-.138(0.047)$ & $0.003 *$ \\
Influence of Money on Judicial Decisions & Knowledge about the Courts and Judges \\
Religious Service Attendance & . & \\
\hline
\end{tabular}

Note. $N=973$. $*$ Statistical Significance $<0.05$, all $\mathrm{p}$-values are based on a two-tailed test.

\section{Conclusions}

The purpose of this paper has been to examine the levels of trust in local courts among racial/ethnic groups living in the United States. Using a multivariate regression analysis I have examined the effects of race/ethnicity on levels of trust in state courts. Additionally, I have controlled for several external variables including age, gender, education, knowledge about the courts and judges, influence of money on judicial decisions and religious attendance. The findings of my research indicate that African Americans have a lower trust levels in state courts in comparison to Caucasians, Hispanics have no more or less trust in state courts in comparison to Caucasians, African Americans and other racial/ethnic minority groups, and other racial/ethnic minority groups are shown to have a higher level of trust in state courts in comparison to African Americans 
and no more or less trust when compared to Caucasian and Hispanic respondents. The findings were in part correct and in part incorrect with my original hypothesizes pertaining to the levels of trust held by minorities. Additionally, this study suggests that further research should be conducted regarding Hispanics and other racial/ethnic groups and their level of trust in state courts. Further research, as suggested by this study, is needed on frequency of religious attendance and levels of trust in state courts and perhaps the United States Supreme Court.

\section{Implications and Limitations of the Study}

I believe that it is necessary to take a closer look at the factors which can influence Hispanic's levels of trust in state courts, given the inconsistent results for Hispanics in this and previous studies. Could the state in which Hispanics live in effect their trust and confidence in state courts? Could citizenship status also be a factor effecting Hispanics trust in state courts? Do Hispanics believe that they are discriminated against in the criminal justice system, if so, what level of discrimination do they believe they face? Does a language barrier effect how Hispanics perceive court system? Does citizenship status among Hispanics influence their trust for the courts (Menjívar \& Bejarano, 2004)? Future researchers conducting studies pertaining to trust in the courts and Hispanics should specifically look into evaluating the trust in courts of states with unfriendly immigration policies, such as Arizona and Texas, and state with friendly immigration policies. These studies should also focus on evaluating the attitudes between native-born and foreign-born Hispanics and understand any difference that may arise. Additionally, I do believe that researches should spend more time examining the trust levels in courts by other minority groups, such as Native American and Asian-American. As discussed previously in the paper, minority groups within the United States have had somewhat of a thorny track record with the American court system therefore it would be worthwhile to examine their trust in state courts.

In addition to these implications, the survey sample had several limitations. One of the major issues of concern was the fact that the survey only offered three clear categories of race and ethnicity. Caucasians, African American, and Hispanic were the only racial and ethnic options offered as a choice for respondents. Individuals identifying with any other racial and ethnic group had little choice in self-identification; they were simply lumped in the category of "other". This particular way of categorizing race and ethnicity is problematic because it lumps a number of other racial/ethnic groups together making it difficult to truly assess the levels of trust in state courts among different racial and ethnic groups. Future studies should seek to offer more racial and ethnic options for participants to choose from. Additionally, the use of "Hispanic" as a racial and ethnic option on the survey can also present some issues. The label of "Hispanic" is often disputed among people who are labeled as such. According to Rumbaut and Portes (2014), immigrant groups from Latin American countries are aware of their commonalities in language and culture, however, those commonalities fail define them in one term. National loyalties and rivalries between Latin American countries promote anything but solidarity between immigrants from those countries. The lumping together of all immigrants originating from Latin American under the common term of "Hispanic" disregards their experiences which may play a significant effect on how they view the court system. Latin American countries with histories of oppressive regimes, such as Colombia, Argentina, and Chile among others, may affect how immigrants from those countries view the criminal justice system (Messing et. al., 2015).Future studies should be mindful of this label and the disagreement over its use. The implications and limitations of this study should be kept in mind in future studies seeking to analyze the levels of trust in state courts among racial and ethnic groups in the United 
States.

\section{Appendix: Variable Measures}

Trust and Confidence in State Courts and Judges: How much trust and confidence do you have in courts and judges in your state? $(1=$ None at All, 2 = Just a Little, $3=$ Some, $4=$ A Great Deal $)$. Respondents who refused to answer the question or didn't know were dropped.

Gender: Respondent Gender ( $1=$ male, $0=$ female). Respondents who refused to answer the question were dropped.

Race/Ethnicity: What is your race? $(1=$ Black; $0=$ Hispanic and Other; $1=$ Hispanic, $0=$ Black and Other; $1=$ Other, $0=$ Hispanic and Black). Respondents who refused to answer the question were dropped.

Knowledge about Courts and Judges: How much would you say you know about what courts and judges do in your state? $(1=\mathrm{A}$ Great Deal/some, $0=$ None at All/Just a Little). Respondents who refused to answer the question were dropped.

Influence of Money in Judicial Decisions: How much influence do you think campaign contributions made to judges have on their decisions - a great deal of influence, some influence, just a little influence, or no influence at all? ( $1=\mathrm{A}$ great deal/some, $0=$ None at All Just a Little). Respondents who refused to answer the question were dropped.

Education: What is the last year of schooling that you have completed? (1=1st -11 th grade, High School Graduate, High School Graduate/No College, $0=$ Some College, College graduate, Post-graduate school). Respondents who refused to answer the question were dropped.

Religious Attendance: How often do you attend religious services - every week, once or twice a month, several times a year, or hardly ever? $(1=$ Every Week, $2=$ Once or Twice a Month, $3=$ Several Times a Year, $4=$ Hardly Ever). Respondents who refused to answer the question were dropped.

Age: In what year were you born? $(0=1911-1967,1=1968-1983)$. Respondents who refused to answer the question were dropped.

\section{References}

Barnes, M. L., \& Chemerinsky, E. (2009). Disparate treatment of race and class in constitutional jurisprudence. Law \& Contemp. Probs, 72, 109.

Benesh, S. C. 2006). Understanding public confidence in American courts. Journal of Politics, 68(3), 697-707.

Buckler, K., et al. (2007). Citizen assessment of local criminal courts: Does fairness matter? Journal of Criminal Justice, 35(5), 524-536.

Eisenberg, T. et al. (2001). Forecasting life and death: Juror race, religion, and attitude toward the death penalty. The Journal of Legal Studies, 30(2), 277-311.

Enomoto, C. E. (1999). Public sympathy for OJ Simpson. American Journal of Economics and Sociology, 58(1), $145-161$.

Fagan, R. W. (1981). Public support for the courts: An examination of alternative explanations. Journal of Criminal Justice, 9(6), 403-417.

Federico, C. M., \&Holmes, J. W. (2005). Education and the interface between racial perceptions and criminal justice attitudes. Political Psychology, 26(1), 47-75.

Gibson, J. L., \& Caldeira, G. A. (1992). Blacks and the United States Supreme Court: Models of diffuse support. The Journal of Politics, 54(4), 1120-1145.

Henderson, M. L., et al. (1997). The impact of race on perceptions of criminal injustice. Journal of Criminal Justice, 25(6), 447-462.

Hurwitz, J., \& Peffley, M. (2005). Explaining the great racial divide: Perceptions of fairness in the US Criminal Justice System. Journal of Politics, 67(3), 762-783. 
Jamieson, K. H., \& Hardy, B. W. (2008). Will ignorance \&partisan election of judges undermine public trust in the judiciary? Daedalus, 137(4), 11-15.

Martinez-Ebers, V. et al. (2000). Latino interests in education, health, and criminal justice policy. Political Science \& Politics 33(3), 547-554.

Menjívar, C., \& Bejarano, C. (2004). Latino immigrants' perceptions of crime and police authorities in the United States: A case study from the Phoenix Metropolitan Area. Ethnic and Racial Studies, 27(1), 120-148.

Messing, J. T, et al. (2015). Latinas' perceptions of law enforcement fear of deportation, crime reporting, and trust in the system. Affilia, 30(3), 328-340.

Odem, M. E. (2008). Unsettled in the suburbs: Latino immigration and ethnic diversity in Metro Atlanta. In A. Singer, S. W. Hardwick \& C. Brettell (Eds.), Twenty-First Century gateways: Immigrant incorporation in suburban America (pp. 105-136). Washington, D.C.: Brookings Institution Press.

Olson, S. M., \& Huth, D. A. (1998). Explaining public attitudes toward local courts. Justice System Journal, $20,41$.

Overby, L. M. et al. (2004). Justice in black and white: Race, perceptions of fairness, and diffuse support for the judicial system in a Southern State. Justice System Journal, 25(2), 159-182.

Rottman, D. B., \& Tomkins, A. J. (1999). Public trust and confidence in the courts: What public opinion surveys mean to judges. Court Review, 36, 24-63.

Rumbaut, R. G., \& Portes, A. (2014). Immigrant America: A portrait. Okland: University of California Press.

Sun, I. Y., \& Wu, Y. N. (2006). Citizens' perceptions of the courts: The impact of race, gender, and recent experience. Journal of Criminal Justice, 34(5), 457-467.

Tyler, T. R. (1988). What is procedural justice-criteria used by citizens to assess the fairness of legal procedures. Law \& Sociology Review, 22, 103.

Tyler, T. R. (2001). Public trust and confidence in legal authorities: What do majority and minority group members want from the Law and Legal Institutions? Behavioral Sciences \& the Law, 19(2), 215-235.

Wenzel, J. P., et al. (2003). The sources of public confidence in state courts experience and institutions. American Politics Research, 31(2), 191-211.

Wisneski, D. C. et al. (2009). Gut reactions moral conviction, religiosity, and trust in authority. Psychological Science, 20(9), 1059-1063.

Young, R. L. (1991). Race, conceptions of crime and justice, and support for the death penalty. Social Psychology Quarterly, 54(1), 67-75.

Young, R. L. (1992). Religious orientation, race and support for the death penalty. Journal for the Scientific Study of Religion, 31, 76-87. 